\title{
The Effect of Escape Route Inforemation on Mobility and Way Finding Under Smoke Logged Conditions
}

\author{
TRULS PAULSEN \\ SINTEF Safety and Reliability, \\ N-7034 Trondheim, Norway
}

\begin{abstract}
Seventy-nine adult subjects had to find their way out of an experimental facility that provided the following information principles: visual discontinuous markings (e.g. signs), visual continuous markings, tactile continuous markings and combination of these principles. The dependent variables were; evacuation time, outcome of evacuation, memory of the escape route geometry, estimated evacuation time and subject's opinion. During evacuation trials the visibility distance was approximately $2.5 \mathrm{~m}$. Analysis of the results indicate that continuous markings are superior to traditional exit signs. On the basis of these and other findings it is recommended that continuous tactile systems are used when expected optical density (OD) during evacuation exceeds 1.5. Visual continuous markings are recommended when $1.5>\mathrm{OD}$ $>0.1$. Traditional exit signs are only recommended when expected $\mathrm{OD}<0.1$.
\end{abstract}

KEY WORDS: exit signs, tactile information, smoke, optical density, mobility, way finding

\section{INTRODUCTION}

Escape route information (ERI) is a necessity in complex spaces and spaces where people are unfamiliar with the escape routes. ERI denotes all information that people need in order to evacuate safely; information about directional changes, information about obstacles and information about exits. Usually this information is presented as visual stimuli; directional signs, illumination of floor, walls and obstacles. In a fire situation, however, the visibility in a building can be reduced as a consequence of electric power failure and /or smoke. A lot of research has therefore been done to find out how people's safety can be maintained under such conditions and design standards have been formulated on this basis. These standards generally prescribe a minimum requirement for escape route lighting, location of signs and a minimum 
requirement for sign luminance and contrast [1] [2]. With respect to smoke logged conditions, incidents like the fire on board the passenger ferry Scandinavian Star [3] has, however, raised question about the adequacy of current design standards. A literature review [4] of the empirical bases for the current standards also gives rise to scepticism. It shows that the research on visibility hazard from smoke mainly has focused on the relation between smoke density and the visibility threshold for signs. Few attempts have been made to evaluate the effect of ERI on way finding and mobility under smoke logged conditions.

Because of the paucity of experimental data that deal with ERI under smoke logged conditions, the following study was commisioned by the Royal Norwegian Council for Scientific and Industrial Research, to broaden the experimental base for these design standards. An extended research report of this study is published by SINTEF - the Foundation for Scientific and Industrial Research at the Norwegian Institute of Technology [5].

The before mentioned literature review revealed only two studies concerning the effect of ERI on way finding and mobility under smoke logged conditions. Edmondo and Mackey [6] evaluated the effect of different types of ERI for emergency egress on Navy ships, whereas Chesterfield, Rasmussen and Dillon [7] evaluated the effect of two different configurations of emergency lights and markings in an aircraft cabin filled with non toxic white smoke.

In both studies cited above was the smoke layered with less smoke near the floor. Consequently the authors recommend that the ERI should be located near the floor. Smoke layering is undoubtedly a phenomenon to take into consideration in aircraft where people are sitting in the room of fire origin. However, in complex spaces it is likely that the escape routes will be homogeneously filled with smoke. This because the smoke from the room of fire origin will be cooled down when it spreads into the escape routes [8]. Hence low located ERI may be of less advantage in complex spaces. Therefore it was proposed to evaluate different configurations of ERI in a condition with homogeneous smoke.

In the time since the cited studies were conducted, several new ERI products have been developed. A common factor for several of these products is that the information is presented continuously along the escape route. For example continuous linear lighting produced either by photoluminescent material or incandescent lamps. We wished to know whether these new products performed better than traditional exit signs under smoke logged conditions.

\section{METHOD}

\section{Subjects}

Forty-six males and thirty-three females age 19 - 25 years old were paid NOK 100 for participating in the experiment. All subjects were university students with normal mobility and normal binocular contrast sensitivity as measured with the Vision Contrast Test System. They all were unfamiliar with the escape route. 
Simulation facility The study took place in an experimental simulation facility at Norwegian Fire Research Laboratory. The facility was built of steel plates and simulated a section of the ferry 'Scandinavian Star' comprising two floors connected with a staircase [3]. The interior was finished with gypsum boards. Detailed layout and dimensions of the simulation facility are shown in Figure 1. First floor consisted of a rectangular corridor with two doors. One of the doors simulated a cabin door leading into the corridor system while the other simulated a door leading into another section of the ship. The second floor consisted of a straight corridor with a door in one end. This door simulated an emergency exit leading out to an open deck. The staircase connecting the two floors had seven steps leading to a half landing. From this half landing the staircase turned $180^{\circ}$ and seven more steps led to the top landing. The risers and treads were 18 and $20 \mathrm{~cm}$ respectively. A thermal image camera was installed nearby the section door in order to record the movements of subjects.

Escape Route The escape route began at the cabin door, followed one side of the rectangular corridor, up the staircase and through the emergency exit to the open deck (see Figure 1). Total length of the escape route, as measured along the centre line, was $29 \mathrm{~m}$.

Smoke Simulation Brandax VS, a product intended for use in fire drills, was used to simulate smoke from a smouldering fire. Ninety-five per cent of the particles in the white coloured smoke produced by this product has a size in the range of $0.3-1.2 \mu \mathrm{m}$. This corresponds fairly well with particle sizes found in smoke from smouldering fires [9]. Smoke from Brandax VS is non toxic but has a strong irritating effect on eyes and upper airways. The smoke was introduced into the ships' section by means of a Rökax smoke generator. Optical Density of the smoke was measured at a location close to the ceiling in the stairway (see Figure 1).

Environment During all evacuation trials the simulated ships' section was homogeneously filled with smoke that held a temperature of about $20^{\circ} \mathrm{C}$. The Optical Density was held constant at $1 / \mathrm{m}$. This corresponds to a visibility distance of about $2.5 \mathrm{~m}$ for a back-lit sign [10]. The reflectance of the interior finish was measured to be 0.55 . The overall lightning in the simulation facility was turned off during all evacuation trials. The illuminance outside the cabin door was $435 \mathrm{~lx}$. This was the illuminance subjects adapted to before entering the escape route.

Measuring Equipment Optical Density was measured with Maurer MG 82-G (Light Source), Maurer ME 82 / 25 - E (Light Receiver) and Maurer ME 82 log (Electronics). Luminance was measured with a Lichtmesstechnik LMT 1006 luminance meter. Illuminances was measured with Lichtmesstechnik LMT Pocketlux luxmeter.

\section{Configurations of Escape Route Information}

Six different configurations of Escape Route Information (ERI) was implemented in the simulated ship's section. 
Discontinuous Visual ERI This configuration was implemented by means of Glamox Emergency Lights. This is a type of back-lit sign consisting of a box with a front board made of opal plastic. Text, symbols and pictograms are displayed on the front board. Letters and arrows appear white against a green background. Pictograms are also shaped in green and white. The front board is illuminated by one or several fluorescent tubes. Several slits in the bottom of the box provide light directed towards the floor. Mean luminance for signs included in the study were $250 \mathrm{~cd} / \mathrm{m}^{2}$.



FIGURE 1. Plan of Simulation Facility and Escape Route.

Appropriate signs were placed to indicate directional changes in the escape route. The emergency exit was also marked with an appropriate sign. In total there was 6 signs, all mounted at head level. This configuration complies to the Norwegian Building Code.

Semi-Continuous Visual ERI This configuration was implemented by means of Lumicae Safety Light. This is a lamp consisting of a cold cathode tube housed in polycarbonate. Text, symbols and pictograms are attached directly on the tube. The length of 
one lamp is approximately $80 \mathrm{~cm}$. Lamps with monochromatic green or white light were used in the experiments. Mean luminance for these lamps was 250 and $440 \mathrm{~cd} / \mathrm{m}^{2}$ respectively.

Lamps with green light were placed at every directional change in the escape route. These lamps had the word "EXIT" and an appropriate directional arrow attached to the tube. The colour of these letters and symbols where black. White lamps with similar text and symbols were placed between the green lamps so the distance from one lamp to the next never exceeded $3 \mathrm{~m}$. All these lamps were mounted on the wall $10 \mathrm{~cm}$ above the floor. In the staircase additional white lamps were mounted on three of the risers. The emergency exit was indicated with an appropriate back-lit sign located above the door (same as in the configuration with high located signs).

Continuous Tactile ERI This configuration was implemented by means of the Safety Rail System. This system is based on an ordinary handrail with 'notches' giving tactile information about the direction towards an emergency exit. The system also features tactile information telling when to cross a corridor and when close to an exit.

The Safety Rail was mounted on both walls in the escape route. The top of the rail was $85 \mathrm{~cm}$ above floor level. The emergency exit was indicated with an appropriate back-lit sign located above the door.

Continuous Visual ERI with High Luminance This configuration was implemented by means of Guide Lite Emergency Lights. This light consists of small incandescent lamps enclosed within modules of extruded polycarbonate: These modules can be connected so the light appears as a continuous stripe. Mean luminance for the modules used in the experiment was $5.5 \mathrm{~cd} / \mathrm{m}^{2}$.

The line was located on the floor against the wall. The line followed the left side of the escape route up to the landing on second floor and continued on the right side forward to the emergency exit. The emergency exit was indicated with an appropriate back-lit sign located above the door.

Continuous Visual ERI with Low Luminance This configuration was implemented by means of Lumilux photoluminecent products. The products used in the experiment were excited with fluorescent light giving a mean illuminance of $130 \mathrm{~lx}$ measured at floor level. When the after glowing products was fully excited the mean luminance was $0.3 \mathrm{~cd} / \mathrm{m}^{2}$.

Appropriate photoluminecent signs were placed to indicate directional changes in the escape route. They were located at head level. Photoluminescent lines were located at floor and walls. The line on the floor followed the centre line of the escape route. The line on the wall was located $80 \mathrm{~cm}$ above floor level. It followed the left side of the escape route up to the landing on second floor and continued on the right side forward to the emergency exit. All treads and risers in the staircase were marked with photoluminescent material. The emergency exit was indicated with an appropriate photoluminecent sign attached to the door panel. The lower edge of this sign was located $30 \mathrm{~cm}$ above floor level. The casing was marked with photoluminecent material. 
Combined Tactile / Visual ERI This configuration was implemented by means of the Safety Rail System and Lumicae Safety Lights. The Safety Rail was installed exactly as in the condition with Continuous Tactile ERI. In addition Lumicae lamps were attached to the under side of the rail. The configuration of the lamps was basically the same as in the condition with Semi-Continuous Visual ERI, but two more lamps were added. One was placed in the beginning of the stairway and the other just before the emergency exit.

\section{Performance Measures}

The different configurations of escape route information were evaluated by means of the following performance measures.

Evacuation Outcome The outcome of an evacuation trial was scored as either Success or Failure. This was done on the basis of data from direct observation during evacuation trials and later observation of thermal image video recordings. Trials containing at least one of the following incidents were scored as Failure:

- $\quad$ the subject made a wrong turn on first directional change on 1 floor

- the subject went out the section door on 1 floor

- the subject went past the stairway and the section door, and continued along the unmarked corridor on 1 floor

the subject tumed and walked back

the subject gave up and asked to be rescued,

the evacuation time exceeded maximum allowable time ( a maximum evacuation time of $3 \mathrm{~min}$ was set for safety reasons. After 3 minutes all evacuation trials were interrupted and a smoke diver went into the ship's section and led the subject out).

Trials without these incidents were scored as Success.

Evacuation Time This performance measure was defined as the time needed for successful escape. It was measured with a hand held stopwatch.

Memory of Escape Route Layout Subjects' memory of the escape route layout was defined as their memory of vertical and horizontal directional changes in the escape route. This was measured by instructing the subjects to make a drawing of the directional changes after they had encountered the escape route. Subjects' drawings were scored against an answer drawing. Minimum score was 0 and maximum 10.

Sense of Time Subjects were asked to estimate their own evacuation time after the evacuation trials. Sense of time was defined as the absolute value of the difference between evacuation time and estimated time.

Subjects Opinion Subject's opinions about escape route information and problems associated with walking in smoke was measured with a questionnaire. Subjects rated on a fourpoint scale how the encountered escape route information supported way finding and mobility (Score 1: very poor, Score 4: very good). They were also asked to indicate which two of the following six effects of fire smoke they found most annoying: 1) unpleasant smell, 2) irritation and pain in the eyes, 3) irritation and pain in mouth and pharynx, 4) breathing difficulties, 5) reduced visibility, 6) feeling of isolation and helplessness. 


\section{Experimental design}

A between-group design was employed. The groups were matched on gender, spatial cognition, and anxiety level. Independent variables were the different configurations of escape route information and dependent variables were the performance measures described in the previous section. Each subject was used only once in order to control for learning effects.

\section{Procedure}

Preparation Session People who wanted to participate in the experiment attended a preparation session. In this session they went through two psychological tests measuring anxiety level and spatial cognition. Anxiety level was measured with the Gissen questionnaire. Spatial cognition was measured with the Rybachoff-Sandefjord test. The tests were administered as group test. After these tests each person went through the Vision Contrast Test, and only persons with normal visual contrast sensitivity were included in the evacuation session. Gender, anxiety level and spatial cognition were used to randomly assign subjects into matched experimental groups.

Evacuation Session In the beginning of the evacuation session all subjects were gathered together and given instruction about their task and safety precautions during evacuation trials. They were told that the subject's task was to find the emergency exit in an escape route filled with smoke, and when doing this they should move as fast as they could without stumbling, colliding with walls, etc. They were told that the smoke had an irritating effect on eyes and throat, but that it was non toxic. A safety instruction was given telling subjects that they could interrupt the evacuation whenever they wanted and ask for assistance if they did not mange to get out of the ship's section by them selves. They were also told that for safety reasons there was a maximum time they were allowed to be exposed to smoke. After this time a smoke diver would come and take them out of the ship's section. They were, however, not informed about the exact value ( 3 minutes) of this maximum time. The task and safety instructions were repeated for each subject before he or she started the evacuation. During evacuation trials all subjects wore comfortable shoes and similar boiler suits.

After the evacuation trial, subjects were taken to a separate room and instructed to fill out the questionnaire. Subjects who had finished their evacuation trial were separated from subjects who had not. This was done in order to prevent communication about the escape route.

The subjects were given no facts about the different configurations of escape route information included in the experiment. An exception from this procedure was subjects encountering tactile information. They were taken to a separate room and shown a section of the Safety Rail. Here they received information about the rail's directional information, but were not, however, informed about the 'corridor changing device' included in the Safety Rail System. All these subjects were instructed to touch and feel the rail with their hands. 


\section{RESULTS}

The results were analysed with the statistical package SPSS/PC+. Separate One-way analysis of variance was carried out for each dependent measure. Some of the data was on a nominal scale that ordinarily calls for nonparametric statistics. Cochran [11] have however shown that the F-statistics can be applied on nominal data, hence nominal data was analysed with ANOVA. But in order to check for sensitivity to ANOVA assumptions, the nominal data were also analysed with the Kruskal-Wallis statistics. All the ANOVA results presented below were in agreement with the results obtained with the Kruskal-Wallis statistics.

\section{Outcome} Table 1.

The frequency of Success and Failure for each configuration of ERI is presented in

TABLE 1. Evacuation Outcome for Six Configurations of Escape Route Information

\section{Outcome}

$\begin{gathered}\text { Configuration of Escape Route } \\ \text { Information }\end{gathered}$
Success

\begin{tabular}{|c|c|c|c|}
\hline Discontinuous Visual ERI & 8 & 4 & 12 \\
\hline Semi-Continuous Visual ERI & 11 & 4 & 15 \\
\hline Continuous Tactile ERI & 13 & 1 & 14 \\
\hline $\begin{array}{l}\text { Continuous Visual ERI with High } \\
\text { Luminance }\end{array}$ & 9 & 0 & 9 \\
\hline $\begin{array}{l}\text { Continuous Visual ERI with Low } \\
\text { Luminance }\end{array}$ & 14 & 1 & 15 \\
\hline Combined Tactile and Visual ERI & 14 & 0 & 14 \\
\hline Total (n) & 69 & 10 & 79 \\
\hline
\end{tabular}

One-way analysis of variance revealed a statistical significant effect of ERI on Outcome $F$ $(5,73)=2.49, p<0.05$. Duncan's multiple-range test, employed to trace the source of this effect, indicated that the difference was between discontinuous and semi-continuous ERI on one hand and continuous ERI on the other. In order to test the hypothesis that level of information continuity affected Outcome, the configurations of ERI were classified as Discontinuous, Semi-Continuous and Continuous (see Table 1). ANOVA carried out on this data revealed a statistically significant effect of information continuity on outcome $F(2,76)=$ $6.12 p<0.01$. Duncan's multiple-range test for these data showed that the outcome for Discontinuous and Semi-Continuous configurations of ERI were significantly different from 
the outcome for Continuous configurations, whereas the difference between Discontinuous and Semi-Continuous configurations were not significant, $p<0.05$.

\section{Evacuation Time}

Mean evacuation time for each configuration of ERI is presented in Table 2. The Levene test of homogeneity of variance indicated that this data should be transformed before applying ANOVA. The evacuation times were therefore transformed to logarithmic values.

TABLE 2. Mean Evacuation Time for Six Configurations of Escape Route Information

\section{Configuration of Escape Route Information \\ Evacuation Time (s) (n)}

Discontinuous Visual ERI

$65.6 \quad 8$

Semi-Continuous Visual ERI

30.5

8

Continuous Tactile ERI

Continuous Visual ERI with High

91.7

45.9

13

Luminance

Continuous Visual ERI with Low

51.7

14

Luminance

Combined Tactile and Visual ERI

The ANOVA carried out on this data revealed a statistical significant effect of ERI configuration, $F(5,63)=11.19, p<0.01$. Duncan's multiple-range test, employed to trace the source of this effect, showed that Continuous Tactile ERI was significant slower, $p<0.05$, than the other ERI configurations with the exception of Discontinuous Visual ERI. Furthermore, the Semi-Continuous Visual ERI was significantly faster, $p<0.05$, than all other ERI configurations. This analysis also showed that Discontinuous Visual ERI was significant slower than Combined Tactile / Visual ERI and Continuous Visual ERI with Low Luminance. An ANOVA with respect to the three levels of information continuity was also carried out. This analysis revealed a significant effect of information continuity, $F(2,66)=8.42, p<0.01$. Duncan's multiple-range test for these data showed that Semi-Continuous configuration of ERI was significantly faster, $p<0.05$, than Discontinuous and Continuous configurations.

The evacuation time data was also analysed with another approach investigating how many subjects succeeded to escape within different time limits. The results from this analysis are presented in Figure 2. Three different time limits were investigated; grand mean (56 seconds), $1 s d$ above grand mean ( 84 seconds) and $2 s d$ above grand mean (112 seconds). In this analysis also subjects who failed to find the emergency exit were given an evacuation time. This time was set equal to the maximum allowable evacuation time of 3 minutes. The results showed that, under only two conditions; Continuous Visual ERI with High Luminance and 
Combined Tactile / Visual ERI, all subjects managed to escape within $2 s d$ above grand mean. In comparison only $67 \%$ had escaped within this time in the condition with Discontinuous Visual ERI.

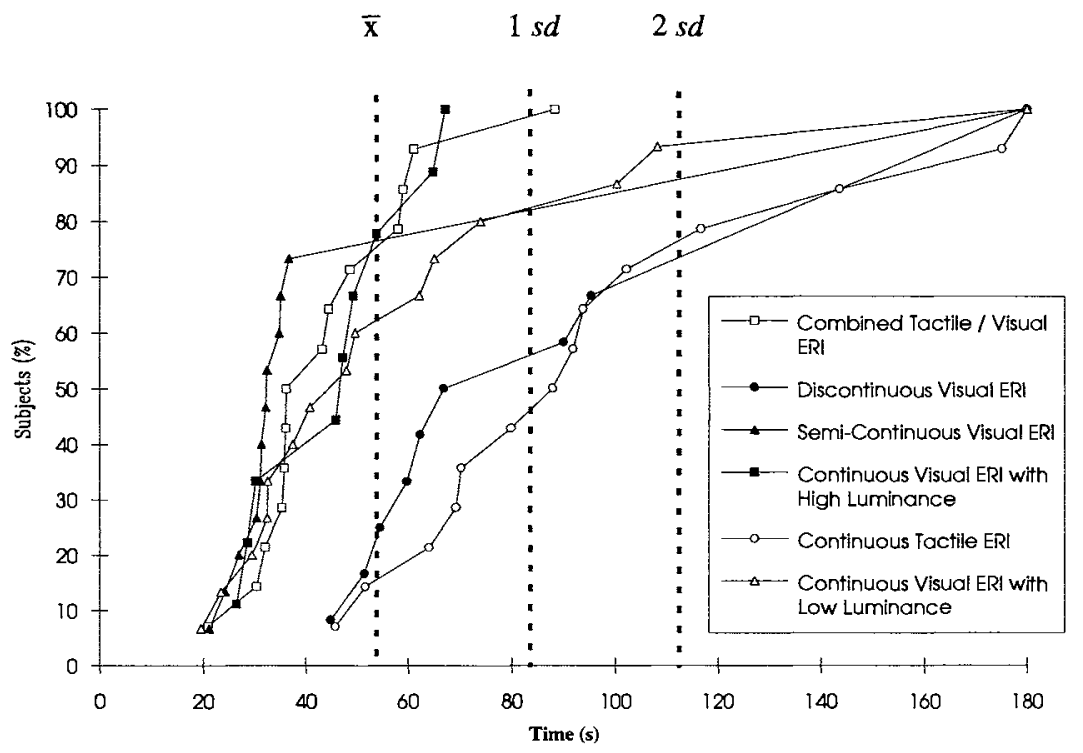

FIGURE 2. Per Cent of Subjects Evacuated per time as a Function of Escape Route Information

\section{Memory for Escape Route}

The ANOVAs carried out on the memory data revealed no significant effects of ERI configuration or level of information continuity.

\section{Sense of Time}

The ANOVAs carried out on the estimated time data revealed no significant effects of ERI configuration or level of information continuity.

\section{Subjects Opinion}

The mean score for way finding and mobility support for each configuration of ERI is presented in Table 3 (Score 1: very poor, Score 4: very good). ANOVA carried out on this data revealed a significant effect of ERI configuration, $F(5,73)=2.34, p<0.05$. Duncan's multiple- 
range test showed that the rating for Discontinuous Visual ERI was significant lower, $p<0.05$, than for Semi-Continuous Visual ERI, Continuous Visual ERI with High Luminance and Combined Tactile / Visual ERI.

TABLE 3. Mean Score for Way Finding and Mobility Support for Six Configurations of Escape Route Information

$\begin{aligned} & \text { Configuration of Escape Route } \\ & \text { Information }\end{aligned}$
Score

$\begin{array}{lcc}\text { Discontinuous Visual ERI } & 2.8 & 12 \\ \text { Semi-Continuous Visual ERI } & 3.8 & 15 \\ \text { Continuous Tactile ERI } & 3.5 & 14 \\ \text { Continuous Visual ERI with High } & 3.8 & 9 \\ \text { Luminance } & 3.1 & 15 \\ \text { Continuous Visual ERI with Low } & & \\ \text { Luminance } & 3.8 & 14 \\ \text { Combined Tactile and Visual ERI } & \end{array}$

Analysis of data from the other items in the questionnaire revealed that the problem experienced by most of the subjects was "reduced visibility", thereafter followed; "irritation and pain in the eyes", "irritation and pain in mouth and pharynx", "unpleasant smell", "breathing difficulties", and "feeling of isolation and helplessness". ANOVA carried out on this data showed that the difference between questionnaire items was significant, $F(5,158)=$ $317.99, p<0.01$. ANOVAs were also carried out in order to investigate differences between ERI configurations, but no significant differences were found.

\section{CONCLUSIONS}

The results show that type of ERI has a significantly effect on peoples' way finding and mobility performance. The ERIs included in the study were different both with respect to frequency of failures, mean evacuation time and subjects' opinion. The results indicate that different ERI systems have different "tolerance" for reduced visibility due to smoke. We therefore recommend that continuous tactile systems are used when expected optical density (OD) during evacuation exceeds 1.5. Visual continuous markings are recommended when 1.5 $>\mathrm{OD}>0.1$. Traditional exit signs are only recommended when expected $\mathrm{OD}<0.1$. 


\section{ACKNOWLEDGEMENTS}

The author would like to thank Ragnar Rosness and Jørn Vatn for their helpful comments concerning this research. Basic founds for the support of the research have been provided by the Royal Norwegian Council for Scientific and Industrial Research, Program for Fire, Explosion and Major Disasters. Additional support has been provided by the following manufacturers: Arne's Trelast A/S, Idéteknikk A/S, Glamox A/S and Norske Hoechst.

\section{REFERENCES}

1. National Fire Protection Association. Life Safety Code, NFPA 101. Section 5-8, Illumination of Means of Egress; 5-9 Emergency Lighting; 5-10 Markings of Means of Egress. Massachusetts: James K. Lathrop, Editor, 1991.

2. Norwegian Lighting Association. Emergency Lighting, Sandvika: Jan-Henrik Audestad, Chairman, 1992 (In Norwegian).

3. Norway's Public Reports. The Scandinavian Star accident. 7 April 1990 (1A Main Report) Oslo: Tore Schei, Chairman, 1990 (In Norwegian).

4. Collins, B.L., Dahir, M.S., Madrzykowski, D. . Evaluation of Exit Signs in Clear and Smoke Conditions (Tech. Report NISTIR 4399). Galthersburg: U.S. Department of Commerce; National Institute, 1990.

5. Paulsen, T., Experimetal Evaluation of Escape Route Information (Tech. Report STF75 A93021). Trondheim: SINTEF - The Foundation for Scientific and Industrial Research at the Norwegian Institute of Technology, 1993 (In Norwegian).

6. Edmondo, P.M. and Macey, H.T., An Investigation of Lighting and Directional Signs for Emergency Egress from Ship's Compartments (Tech. Report 2661) Annapolis: Naval Ship Research and Development Center,1968.

7. Chesterfield, B.P., Rasmussen, P.G and Dillon, R.D., Emergency Cabin Lighting Installations: An Analysis of Ceiling - vs. Lower Cabin-mounted Lighting During Evacuation Trials. Oklahoma: Federal Aviation Administration Civil Aeromedical Institute, 1981.

8. Meland, $\varnothing$. and Lønvik, L.E., Smoke detection. Report from full scale fire test at the school of Vesterskaun January 1989 (Tech. Report STF25 A89010). Trondheim: SINTEF - The Foundation for Scientific and Industrial Research at the Norwegian Institute of Technology, 1989 (In Norwegian).

9. Bankstone, C.P., Cassanova, R.A., Powell, E.A. and Zin, B.T., "Detailed measurements of the physical characteristics of smoke particulates generated by flaming materials", Journal of Fire and Flammability $\underline{8}, 395,1977$.

10. Brown, S.K. and Martin, K. G., A review of the visibility hazard from smoke in building fires. Commonwealth Scientific and Industrial Research Organization, Division of Building Research, Australia, 1981.

11. Cochran, W.G., "The comparison of percentages in matched samples", Biometrica, 37, 256-266, 1950. 